\title{
UMA EXPERIÊNCIA DE INTEGRAÇÃO PEDAGÓGICA DE PAISAGISMO E URBANISMO
}

\author{
AN EXPERIENCE INTEGRATING LANDSCAPE ARCHITECTURE AND URBANISM
}

\author{
AFONSO, Sonia \\ Doutora em arquitetura e urbanismo pela FAUUSP. Professora Adjunto IV do Departamento de Arquitetura \\ e Urbanismo da UFSC. E-mail: soniaa@arq.ufsc.br
}

\section{VAZ, Nelson Popini}

Doutor em urbanismo pelo Instituto de Urbanismo de Paris, Universidade de Paris XII - Val de Marne, França. Professor Adjunto IV do Departamento de Arquitetura e Urbanismo da UFSC. E-mail: popini@mbox1.ufsc.br

\section{RESUMO}

Este artigo tem por objetivo apresentar uma experiência de ensino de Paisagismo no Curso de Graduação em Arquitetura e Urbanismo da Universidade Federal de Santa Catarina. Urbanismo \& Paisagismo III faz parte de uma seqüência de disciplinas oferecidas ao longo de sete semestres, onde estes conteúdos pertinentes ao campo de atuação do Arquiteto e Urbanista são abordados em suas diferentes escalas. Este documento apresenta inicialmente a relação da disciplina com a estrutura da seqüência, no modo como ela foi proposta na revisão curricular de 1996. Em seguida apresenta a disciplina resultante, produto da evolução da mesma, desde a sua criação no segundo semestre de 1998 até o ano de 2005, perfazendo 14 semestres, buscando realizar uma avaliação da mesma. Como resultado, concluímos que a experiência sugere reavaliar princípios relacionados aos campos de conhecimento do Urbanismo e do Paisagismo, considerando a sobreposição de conteúdos e a interdisciplinaridade proposta pelo currículo.

\section{Palavras-chave: Educação, arquitetura paisagística, urbanismo.}

\begin{abstract}
This paper aim to present an experience of education in Landscape Design at the Undergraduate School of Architecture and Urbanism of the Federal University of Santa Catarina. Urbanismo \& Paisagismo III is a part of a sequence of disciplines offered throughout seven semesters, where these pertinent contents to the performance field of Architects and City Planners are boarded in its different scales. This document presents initially the relation of disciplines with the structure of the sequence, in the way as it was proposed in the curricular revision of 1996. After that it presents the resultant discipline, product of the evolution of the same one, since its creation in the semester of 1998 until the year of 2005, during 14 semesters, searching to carry through an evaluation of the same one. As result, we conclude that the experience suggests reevaluate principles related to the fields of knowledge of Urbanism and of the Landscape Architecture, being considered the overlapping of contents and the interdisciplinarity proposed by the curriculum.
\end{abstract}

Key words: Education, landscape architecture, urbanism.

\section{Introdução}

A disciplina Paisagismo não se configurava como exigência curricular na origem dos cursos de Arquitetura e Urbanismo e ainda hoje comparece de forma isolada nesses currículos. Mesmo naqueles cursos onde diversas disciplinas obrigatórias e optativas tratam de questões ligadas ao Urbanismo e ao Paisagismo não há interface entre esses campos do conhecimento. As disciplinas de Urbanismo são frequentemente atribuídas ao campo de estudo teórico-crítico, em paralelo ao projeto de Arquitetura nas suas várias escalas, este sempre caracterizado basicamente por práticas chamadas de "ateliê". 
Quanto a Paisagismo, nas diferentes grades curriculares comparece como disciplina teórica, ora como disciplina de projeto.

A reforma que resultou no currículo vigente atualmente no Curso de Arquitetura e Urbanismo da Universidade Federal de Santa Catarina trouxe uma novidade ao propor a integração destes diferentes campos, reunindo-os em disciplinas como Projeto e Paisagismo I, Urbanismo e Paisagismo II, III e IV, que trabalham tanto os aspectos conceituais do Urbanismo e do Paisagismo quanto à prática projetual, considerada nas diferentes escalas.

Do currículo anterior faziam parte apenas duas disciplinas de Paisagismo, sendo Paisagismo I de 4 créditos oferecida no quarto semestre e Paisagismo II de 3 créditos oferecida como optativa. Paralelamente eram oferecidas disciplinas de Planejamento Arquitetônico do primeiro ao décimo semestre, desde Introdução ao Projeto até o Trabalho de Graduação. A seqüência de Urbanismo, incluía três disciplinas, sendo Urbanismo I e II de 3 créditos e Urbanismo III de 4 créditos.

Em 1996 a estrutura curricular foi revista, sendo a seqüência de Projeto Arquitetônico reduzida, passando a ser ministrada do primeiro ao oitavo semestre, excluído o sexto, possuindo em média 8 créditos semanais. Os conteúdos de Paisagismo foram então distribuídos entre as disciplinas de Projeto Arquitetônico (Introdução e Projeto I da primeira e segunda fases) e de Urbanismo, que passaram a ser consideradas disciplinas de ateliê, oferecidas do quinto ao sétimo semestre com 6 créditos.

O Trabalho de Conclusão de Curso, com temas de livre escolha do estudante, passou a admitir produtos de natureza teórica, do campo do planejamento urbano, ou projetos de edificações, urbanísticos ou paisagísticos.

As ementas das disciplinas do tronco de Urbanismo e Paisagismo, expostas a seguir, podem melhor ilustrar essas seqüências, no modo como foram então concebidas. Essas referências básicas têm orientado a feitura dos planos de ensino das disciplinas do tronco.

\section{ARQ 5631 - INTRODUÇÃO AO PROJETO DE ARQUITETURA E DO URBANISMO (120 H/A)}

Abordagem interdisciplinar. Percepção da construção histórica da cidade. Desenvolvimento da criatividade. Modelos interpretativos. Morfologia paisagística. Compreensão das diversas escalas. Repertório conceitual. Introdução de correntes da Arquitetura e do Urbanismo. Leitura e representação de fragmentos da cidade. Propostas de intervenção em pequenos trechos.

\section{ARQ 5633 - PROJETO ARQUITETÔNICO E PAISAGISMO I - (120 H/A)}

Objeto/ambiente. Estudo do objeto em relação ao homem e ao ambiente. Criação de lugares. Análise, conceituação e proposição de objetos e ambientes, introduzindo estudos de ergonomia e enfatizando o aprendizado a partir da materialidade e da tridimensionalidade. Ambiente e meio ambiente na configuração da paisagem. Condicionantes físicos da paisagem natural e construída. Leitura e conceituação e lançamento de proposta paisagística para setor pré-determinado.

\section{ARQ 5602 - URBANISMO I - (90 H/A)}

Introdução aos conceitos de planejamento, desenho e gestão urbana. A construção histórica do espaço da cidade. Espaço simbólico. Preservação do Patrimônio histórico e cultural. Memória e identidade cultural. Revitalização de áreas históricas. A centralidade urbana. As experiências mundiais e nacionais. Projeto urbano de intervenção em áreas de preservação. 
ARQ 5603 - URBANISMO E PAISAGISMO II - (90 H/A)

O homem e o ambiente. Condicionantes econômicos, históricos e sociais. Valorização e preservação dos recursos naturais. Assentamentos humanos. Processo de ocupação do espaço construído. Habitat. Políticas de preservação ambiental. Análise e projeto paisagístico. Projeto de organização espacial.

\section{ARQ 5605 - URBANISMO E PAISAGISMO III - (90 H/A)}

A cidade. Dinâmica do crescimento urbano. Forma, função e estrutura urbana. Elementos estruturadores do espaço urbano. Uso e valorização do solo urbano. Serviços e equipamentos. Anteprojeto em áreas de renovação urbana.

\section{ARQ 5606 - URBANISMO E PAISAGISMO IV - (90 H/A)}

Planejamento urbano. Diretrizes de desenvolvimento urbano. Preservação cultural e ambiental. Circulação e transportes. Planos setoriais. Legislação urbanística. Políticas públicas e gestão municipal. Sistemas urbanos. Projetos estruturadores do espaço urbano.

ARQ 5607 - URBANISMO V - (90 H/A)

Espaço micro-regional. Processo de conurbação e polarização. Desenvolvimento econômico e organização espacial. Planejamento de gestão ambiental. Legislação e política de zoneamento. Organização do espaço micro-regional. Distribuição espacial de atividades. Políticas públicas e gestão. Projeto urbano de estruturação do espaço micro-regional.

As ementas correspondem às disciplinas situadas no tronco de Urbanismo e Paisagismo, conforme organograma exposto a seguir.

\begin{tabular}{|c|c|c|c|c|c|c|c|c|c|}
\hline \multicolumn{3}{|c|}{$\begin{array}{l}\text { I UNIDADE } \\
\text { INTRODUÇÃO }\end{array}$} & \multicolumn{4}{|c|}{$\begin{array}{l}\text { II UNIDADE } \\
\text { DESENVOLVIMENTO }\end{array}$} & \multicolumn{3}{|c|}{$\begin{array}{l}\text { III UNIDADE - TCC } \\
\text { APROFUNDAMENTO }\end{array}$} \\
\hline $1^{\mathrm{a}}$ fase & $2^{2 \mathrm{a}}$ fase & 3 a fase & $4^{\mathrm{a}}$ fase & 5 a fase & $6^{\mathrm{a}}$ fase & $7 \mathrm{a}$ fase & 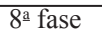 & $9^{a \mathrm{a}}$ fase & $10^{\mathrm{a}}$ fase \\
\hline & 30 & 28 & 30 & 32 & 27 & 24 & & & \\
\hline $\begin{array}{l}\text { EGR } \\
5611 \\
(6)\end{array}$ & $\begin{array}{l}\text { EGR } \\
5612 \\
(6) \\
\end{array}$ & & & & & & & & \\
\hline $\begin{array}{l}\text { EGR } \\
5605 \\
\text { (4) }\end{array}$ & & $\begin{array}{l}\text { EGR } \\
5607 \\
(4) \\
\end{array}$ & & & & & & & \\
\hline $\begin{array}{l}\text { ARQ } \\
5631 \\
(6+2) \\
\end{array}$ & $\begin{array}{l}\text { ARQ } \\
5633 \\
(8) \\
\end{array}$ & $\begin{array}{l}\text { ARQ } \\
5634 \\
(8+2) \\
\end{array}$ & $\begin{array}{l}\text { ARQ } \\
5635 \\
(6+2) \\
\end{array}$ & $\begin{array}{l}\text { ARQ } \\
5636 \\
(6+2) \\
\end{array}$ & & $\begin{array}{l}\text { ARQ } \\
5637 \\
(6+2) \\
\end{array}$ & $\begin{array}{l}\text { ARQ } \\
5638 \\
(8) \\
\end{array}$ & $\begin{array}{l}\text { ARQ } \\
5639 \\
(8) \\
\end{array}$ & \\
\hline & & & & & $\begin{array}{l}\text { ARQ } \\
5617 \\
(3) \\
\end{array}$ & $\begin{array}{l}\text { ARQ } \\
5618 \\
(3) \\
\end{array}$ & & $\begin{array}{l}\text { ARQ } \\
5680 \\
(1+3) \\
\end{array}$ & $\begin{array}{l}\text { ARQ } \\
5681 \\
(2+2) \\
\end{array}$ \\
\hline & $\begin{array}{l}\text { ECV } \\
5631 \\
(4) \\
\end{array}$ & & $\begin{array}{l}\text { ARQ } \\
5602 \\
(4+2) \\
\end{array}$ & $\begin{array}{l}\text { ARQ } \\
5603 \\
(6) \\
\end{array}$ & $\begin{array}{l}\text { ARQ } \\
5605 \\
(6) \\
\end{array}$ & $\begin{array}{l}\text { ARQ } \\
5606 \\
(6) \\
\end{array}$ & $\begin{array}{l}\text { ARQ } \\
5607 \\
(4+2) \\
\end{array}$ & & \\
\hline $\begin{array}{l}\text { ARQ } \\
5621 \\
(4) \\
\end{array}$ & $\begin{array}{l}\text { ARQ } \\
5622 \\
(4) \\
\end{array}$ & & $\begin{array}{l}\text { ARQ } \\
5623 \\
(4) \\
\end{array}$ & $\begin{array}{l}\text { ARQ } \\
5624 \\
(4) \\
\end{array}$ & $\begin{array}{l}\text { ARQ } \\
5625 \\
(4) \\
\end{array}$ & & $\begin{array}{l}\text { ARQ } \\
5626 \\
(3) \\
\end{array}$ & $\begin{array}{l}\text { ARQ } \\
5627 \\
(4) \\
\end{array}$ & \\
\hline & & $\begin{array}{l}\text { ARQ } \\
5614 \\
\text { (3) } \\
\end{array}$ & & & $\begin{array}{l}\text { ARQ } \\
5612 \\
(2)\end{array}$ & $\begin{array}{l}\text { ARQ } \\
5615 \\
(2) \\
\end{array}$ & $\begin{array}{l}\text { ARQ } \\
5616 \\
\text { (2) }\end{array}$ & $\begin{array}{l}\text { ARQ } \\
5619 \\
(2) \\
\end{array}$ & \\
\hline $\begin{array}{l}\text { ARQ } \\
5641 \\
(4) \\
\end{array}$ & $\begin{array}{l}\text { ARQ } \\
5642 \\
\text { (3) }\end{array}$ & & $\begin{array}{l}\text { ECV } \\
5643 \\
\text { (4) } \\
\end{array}$ & $\begin{array}{l}\text { ECV } \\
5644 \\
(3) \\
\end{array}$ & $\begin{array}{l}\text { ECV } \\
5610 \\
(3)\end{array}$ & & & & \\
\hline & $\begin{array}{l}\text { ARQ } \\
5640 \\
(5)\end{array}$ & $\begin{array}{l}\text { ECV } \\
5645 \\
(5) \\
\end{array}$ & & $\begin{array}{l}\text { ECV } \\
5647 \\
(4)\end{array}$ & $\begin{array}{l}\text { ECV } \\
5648 \\
(5)\end{array}$ & $\begin{array}{l}\text { ECV } \\
5649 \\
(2) \\
\end{array}$ & $\begin{array}{l}\text { ECV } 50 \\
\text { (2) }\end{array}$ & & \\
\hline & & $\begin{array}{l}\text { ARQ } \\
5661 \\
(4) \\
\end{array}$ & $\begin{array}{l}\text { ARQ } \\
5662 \\
(4)\end{array}$ & $\begin{array}{l}\text { ARQ } \\
5663 \\
(4) \\
\end{array}$ & $\begin{array}{l}\text { ARQ } \\
5664 \\
(4)\end{array}$ & & & & \\
\hline & & $\begin{array}{l}\text { FSC } 5616 \\
\text { (2) }\end{array}$ & $\begin{array}{l}\text { ARQ } \\
5655 \\
\text { (4) }\end{array}$ & $\begin{array}{l}\text { ARQ } \\
5656 \\
(3) \\
\end{array}$ & & $\begin{array}{l}\text { ARQ } \\
5657 \\
(3) \\
\end{array}$ & & & \\
\hline
\end{tabular}




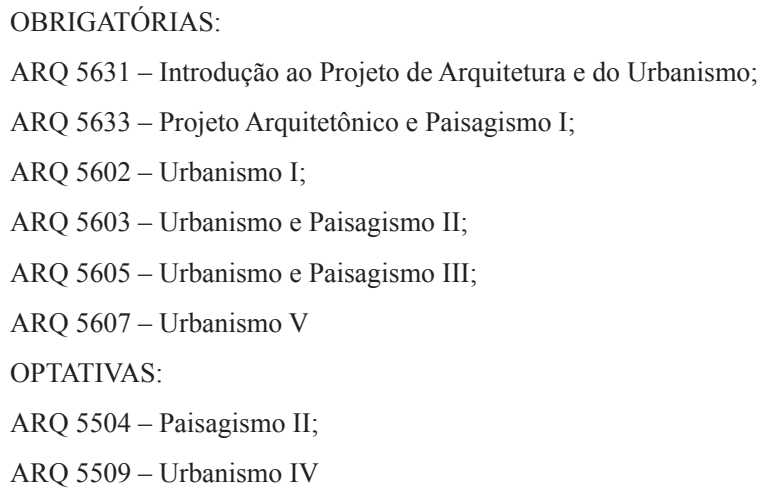

Tabela 1: Grade Curricular do ARQ/CTC/UFSC vigente desde 1996, destacando a seqüência de Disciplinas onde comparecem conteúdos de Urbanismo e Paisagismo

O conjunto das ementas permite verificar a presença de conteúdos teóricos e de conteúdos relacionados ao exercício de projeto, compreendendo então a prática de pesquisa e proposição a ser experimentada pelo estudante.

Observando as ementas da seqüência pode-se destacar o objeto básico da disciplina Urbanismo e Paisagismo III como sendo A CIDADE. A ementa da disciplina limita-se a especificar tópicos referentes a um conteúdo teórico, mencionando categorias como forma, função e estrutura, acrescentando alguns aspectos do processo de urbanização. Define tarefas relacionadas a projeto como intervenções de renovação urbana.

Foram acrescentados no plano de ensino da disciplina, como conteúdo de aula expositiva e seminários, os aspectos relacionados à formação do paisagista, aos métodos de análise visando avaliar realidades urbanas, os principais processos de intervenção urbanística e paisagística, conceitos de espaço público, espaço privado, espaço livre, funções urbanas.

Aspectos operacionais de pesquisa concernentes à área de intervenção, como coleta de dados estatísticos, cartográficos e históricos também têm sido introduzidos tanto como conteúdo de aula expositiva, quanto nos procedimentos de assessoramento ao trabalho dos estudantes.

\section{Plano de ensino da disciplina}

Estudando a ementa e o contexto curricular optou-se por oferecer conteúdos teóricos básicos no início do semestre e estimular o aprofundamento da experiência projetual dos estudantes através de exercícios aplicados ao tratamento de diversas escalas, desde a análise do contexto regional e urbano até a escala local.

No primeiro exercício, um recorte espacial da cidade é escolhido pela equipe como objeto de intervenção. Para não limitar o estudo ao fragmento, busca-se estimular o estudo das relações funcionais que o fragmento estabelece com a cidade e a região, assim como suas características morfológicas internas e o seu processo histórico evolutivo. O segundo exercício objetiva propor intervenções na escala do fragmento, ressaltando-se a importância dos espaços públicos em suas condicionantes ambientais e sociais. O terceiro exercício sintetiza essas proposições, expondoas num conjunto coerente e detalhando um fragmento menor do conjunto. $O$ trabalho final é apresentado em pranchas $A 1$ acompanhadas dos exercícios gravados em CD.

Para permitir uma intervenção projetual de caráter paisagístico, o objeto básico de intervenção são os espaços públicos potencialmente caracterizados como lugares com centralidade: espaços livres configurados por edificações de uso misto apresentando em seu conjunto uso intenso e diversificado, mas que apresentam pontos de conflito. O objetivo central é reordenar os espaços existentes, dando-lhes usos contemporâneos através de novos projetos urbanos. 
Assim, pode-se classificar a experiência como situada na interface do Urbanismo e do Paisagismo, ressaltando-se que as questões relacionadas à paisagem urbana em suas diversas escalas acompanham o tratamento dado nas aulas expositivas e nos assessoramentos às equipes.

A maior parte do trabalho foi proposta como atividade de ateliê, assistida constantemente pelos professores e buscando favorecer o aprofundamento da experiência projetual de cada estudante.

\section{Histórico da disciplina}

Desde o segundo semestre de 1998 até o início de 2005 foram ministradas aulas para 477 estudantes de graduação em Arquitetura e Urbanismo. Ao longo desse período, houve uma busca constante de aperfeiçoar os planos de ensino nos sucessivos semestres, adaptando-os às condições e sugestões trazidas pela implantação da experiência. Houve reformulações de conteúdo de aulas expositivas e uma progressiva simplificação dos exercícios, visando melhores resultados.

Com a criação do PósARQ - Programa de Pós-Graduação em Arquitetura e Urbanismo'a disciplina vem contando com a participação de mestrandos que realizam Estágio de Docência. Em breve o AU-Cidade - Programa de Pós-Graduação em Urbanismo, História e Arquitetura da Cidade $^{2}$ deverá igualmente demandar a participação de seus alunos na disciplina. A prática tem demonstrado os benefícios do estágio docência tanto para os alunos, como para os estagiários e para a disciplina. ${ }^{3}$

O Plano de Ensino ${ }^{4}$ apresentado a seguir, bem como os exercícios propostos resultam das experiências de pós-graduação vivenciadas pelos professores da disciplina, compreendendo: Análise Histórico Estrutural ${ }^{5}$, Condicionantes Geotécnicos ${ }^{6}$, Princípios Paisagísticos e Ambientais ${ }^{7}$, Relações Regionais ${ }^{8}$ e Espaços de Interação e Comunicação?.

\section{Plano de ensino detalhado}

Ementa: A CIDADE. Dinâmica do crescimento urbano. Forma, função e estrutura urbana. Elementos estruturadores do espaço urbano. Uso e valorização do solo urbano. Serviços e equipamentos. Anteprojeto em áreas de renovação urbana.

\section{Objetivos da disciplina}

1. Exercitar a capacidade criativa do estudante no enfrentamento de problemáticas urbanas.

2. Permitir experimentação de métodos de intervenção aplicados a estruturas ambientais urbanas.

3. Desenvolver capacidades de observação, de análise e de criação aplicados à paisagem urbana.

4. Estimular a formulação de propostas de intervenção que contemplem aspectos funcionais, formais, simbólicos e ambientais inerentes à paisagem urbana.

Objeto de estudo: A paisagem de espaços públicos livres centrais da cidade e seu processo de adaptação a condicionantes ambientais e à demanda de conforto e salubridade dos seus usuários.

Método: Experimentação e proposição espacial aplicada à área-objeto, considerando o contexto urbano-regional e as condições locais. Ampliação da experiência de proposição paisagística, orientada pela observação dos modos de uso e ocupação do espaço e das necessidades dos usuários. Procedimentos baseados nas observações de campo, levantamentos, investigação bibliográfica, entrevistas. 


\section{Etapas}

Trabalho semestral desenvolvido através de três etapas, em equipe (de no máximo três estudantes) ou de modo individual.

Exercício 1 - Análise do contexto regional e urbano da área escolhida, destacando-se:

- a formação da configuração atual da área;

- relações estabelecidas com as estruturas espaciais urbano-regionais;

- características da área: sistemas de circulação, infra-estrutura, instalações e serviços;

- levantamento e análise das formas de parcelamento e ocupação do solo, da legislação urbanística e dos pontos de conflito de usos e fluxos;

- estimativa das demandas dos usuários.

Exercício 2 - Reorganização da paisagem da área, considerando os dados apurados e programas funcionais sugeridos pela disciplina.

Exercício 3 - Síntese dos dados gerais da área, com detalhamento de fragmento da área, definindo materiais aplicados, mobiliário urbano e espécies vegetais a serem utilizados.

\section{Observações complementares}

- As aulas são desenvolvidas como palestras sobre temas da ementa e relacionadas com o desenvolvimento do trabalho; sessões de assessoramento individual, em equipe e para o conjunto dos trabalhos; painéis de exposição e debate acerca dos resultados obtidos em cada etapa.

- Avaliações individuais são divulgadas após a conclusão de cada etapa.

- As sessões de assessoramento podem ser utilizadas para obter apoio metodológico, localizar fontes de dados específicos e para orientação bibliográfica complementar. Buscar dados na internet, com especialistas e usuários da área de estudo.

- Os trabalhos devem ser desenvolvidos em sala e no horário das aulas. Procedimentos externos devem ter autorização prévia dos professores.

\section{Critérios de avaliação do desempenho do estudante}

Freqüência e participação ativa nas aulas. Evolução ao longo do semestre. Enfrentamento dos problemas em cada etapa. Pontualidade na entrega e apresentação do trabalho em painel. Qualidade da apresentação gráfica, da exposição e do conteúdo dos estudos e projetos.

\section{Programação}

Aula 1 - Interconhecimento, exposição e debate acerca do plano de ensino da disciplina.

Aula 2 - Seminário: Arquitetura da Paisagem. Antecedentes e perspectivas da profissão. Escolha da área de estudo.

Aula 3 - Seminário: As Intervenções Espaciais nos Espaços Públicos Livres. Apresentação das propostas de trabalho.

Aula 4 - Seminário: Uma Estrutura de Análise e Seis Alternativas de Intervenção. Conclusão das apresentações.

Aula 5 - Seminário: Espaços Públicos e Espaços Livres. Entrega das propostas de trabalho por escrito.

Aula 6 - Visita a campo. 
Aula 7 - Seminário: Coleta de dados.

Aulas 8 a 16 -. Definição dos elementos da etapa I. Assessoramento. Três sessões de painel de apresentação do primeiro exercício.

Aulas 17 a 25 - Definição do Exercício 2. Assessoramento. Painel de discussão das propostas. Aulas 26 a 30 - Definição da etapa final. Assessoramento. Exposição e entrega do trabalho final.

\section{Exercício 1 - Tipologias morfológicas urbanas}

Objetivo: analisar a morfologia, as formas de parcelamento do solo e a legislação urbanística da área de estudo em confronto com os padrões de uso e as atividades observados em seus espaços livres de edificação.

Método: Na cidade escolhida para o estudo, deverá ser inicialmente definido um bairro para a intervenção projetual, cujos padrões de uso do solo expressem uma centralidade real ou potencial, procedendo-se à sua análise conforme os seguintes itens:

1. Análise do contexto regional e urbano onde está inserido o bairro (inserção da cidade na rede urbana, posição do bairro na estrutura urbana, usos de solo existentes, sistema de circulações e de acesso ao bairro).

2. Elaboração de uma Planta Base de um fragmento do bairro estudado, ou seja, de um trecho urbano de não menos que 12 hectares $\left(120.000 \mathrm{~m}^{2}\right.$ ), escolhendo-se uma escala (preferencialmente 1:2000). A planta base deve conter os dados básicos do meio físico (†opografia, rios, vegetação) e do meio construído (cadastro viário e cadastro imobiliário).

3. Identificação da estrutura morfológica básica do trecho urbano - através de esquemas gráficos que identifiquem o seu suporte físico natural, os padrões de parcelamento do solo, a volumetria das edificações e a tipologia dos espaços livres.

4. Registro dos padrões de uso dos espaços livres públicos e privados do trecho com avaliação das condições de uso e carências.

5. Registro do papel da vegetação na morfologia da paisagem local (se estrutural ou complementar).

6. Localização dos principais problemas encontrados no trecho: os pontos de conflito dos usos e atividades, as condições de circulação e acesso, as relações das atividades locais com os sistemas de atividades da cidade;

7. Mapeamento das hipóteses de projeto (contendo as propostas de intervenção no trecho), apresentando-se os possíveis resultados na forma de ideogramas (esquemas gráficos que detalham o partido adotado) acompanhados de texto explicativo.

As referências utilizadas na pesquisa deverão ser citadas ao final do exercício, juntamente com a bibliografia de apoio. Formato da apresentação: gráfico e sintético, em pranchas $A 3$, sem o apoio de material rígido. Os trabalhos serão individuais ou em equipes de no máximo três pessoas.

\section{Exercício 2 - Projeto da paisagem urbana}

Objetivo: A partir das constatações efetuadas no Exercício 1 (que abordou a análise e a compreensão do contexto urbano) desenvolver propostas paisagísticas na área escolhida, conforme sugestões de programa funcional. Exercício com caráter experimental e criativo. 
Método: Destacar na unidade espacial escolhida (bairro, área central, distrito) uma área de aproximadamente 1 hectare para executar intervenções paisagísticas, respondendo às seguintes sugestões de programa:

PROPOSTA 1 - Definir na unidade espacial a área mais adequada para conter adensamento da ocupação habitacional, considerando-se as projeções de crescimento da cidade e da unidade para um horizonte de 20 anos. Estabelecer um plano de massas do setor, destinando $50 \%$ da área projetada aos espaços livres.

PROPOSTA 2 - Localizar na unidade espacial cinco espaços públicos destinados a práticas de lazer e de sociabilidade para a população segundo as seguintes sugestões de programa:

- uma área pública de lazer contemplativo;

- uma ou mais praças de vizinhança;

- uma praça temática (observar as características culturais da população local);

- uma área de práticas desportivas;

- um viveiro de plantas (para manutenção e com objetivos educacionais).

PROPOSTA 3 - Projetar na unidade espacial espaços destinados à preservação ambiental e cultural. Verificar a possibilidade de recuperação de faixa de proteção de curso d'água, de orla marítima ou lacustre, de área florestal ou encosta, de manguezal ou duna. As áreas poderão ser organizadas em conjunto como parque, jardim público ou como um núcleo histórico - cultural.

FORMATO DA APRESENTAÇÃO FINAL: 3 pranchas Al - cada uma contendo a proposta desenhada em planta, cortes e perspectiva axonométrica numa escala adequada (sugere-se a esc. 1:1000), acompanhados de croquis mostrando como o pedestre perceberia os espaços se estivesse caminhando por ali. Um texto explicativo sintético deve apoiar a proposta, caso seja necessário. As referencias utilizadas para a pesquisa deverão ser listadas juntamente com a bibliografia.

\section{Exercício 3 - Projetando espaços livres}

Objetivos: com base no Exercício I e valendo-se das três propostas do Exercício II, elaborar um projeto paisagístico para a área de estudo, detalhando um fragmento dessa área.

1. Devem ser recuperados do Exercício 1 os seguintes elementos:

Planta mostrando esquematicamente as vinculações do bairro com a cidade (Figura 1).

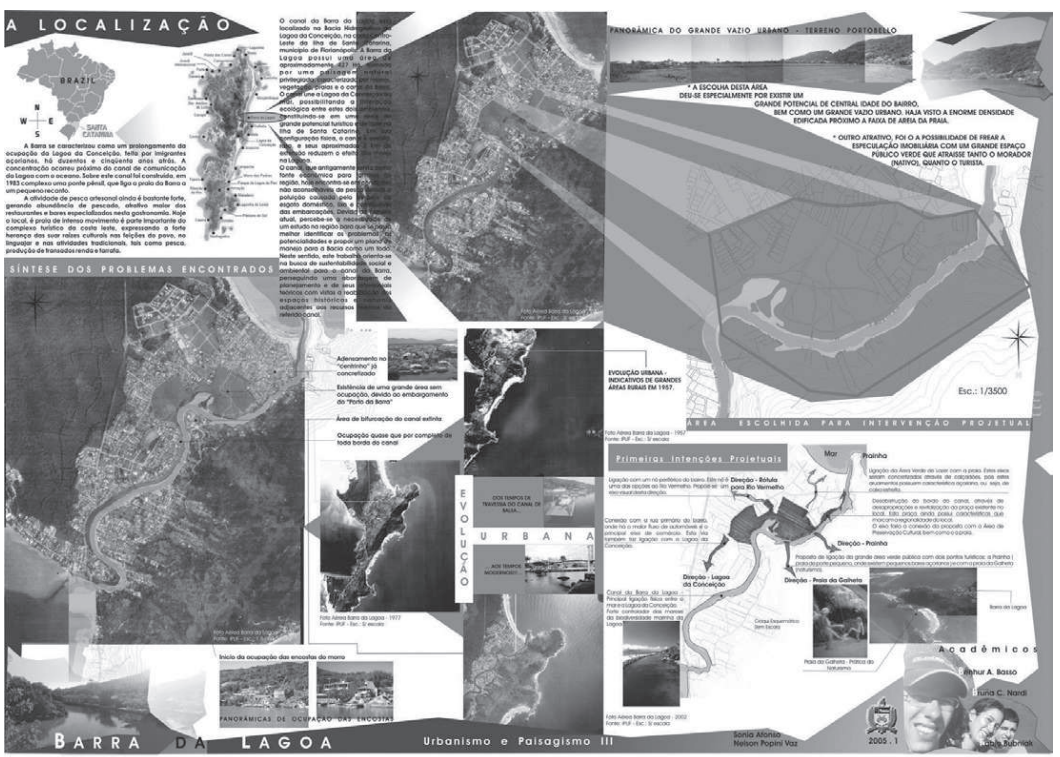

Figura 1: Análise regional e localização 
Planta base com síntese dos problemas encontrados.

Planta base com as Hipóteses de Projeto (Figura 2).

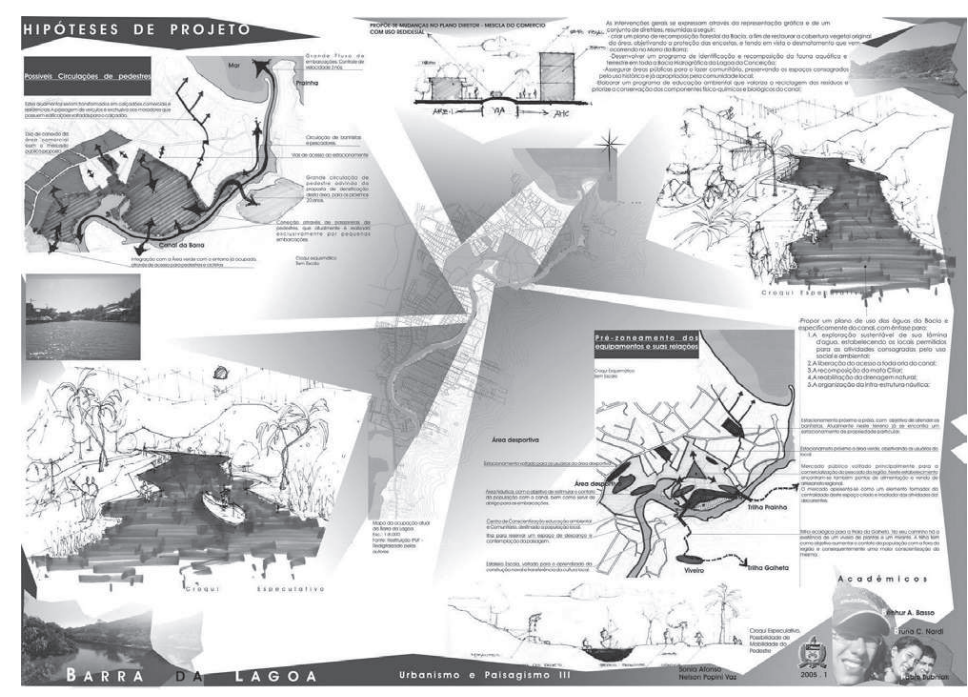

Figura 2: Hipóteses de projeto

2. Deve ser recuperado do Exercício 2:

A planta com a (as) proposta (s) implantada (s). (Figura 3)

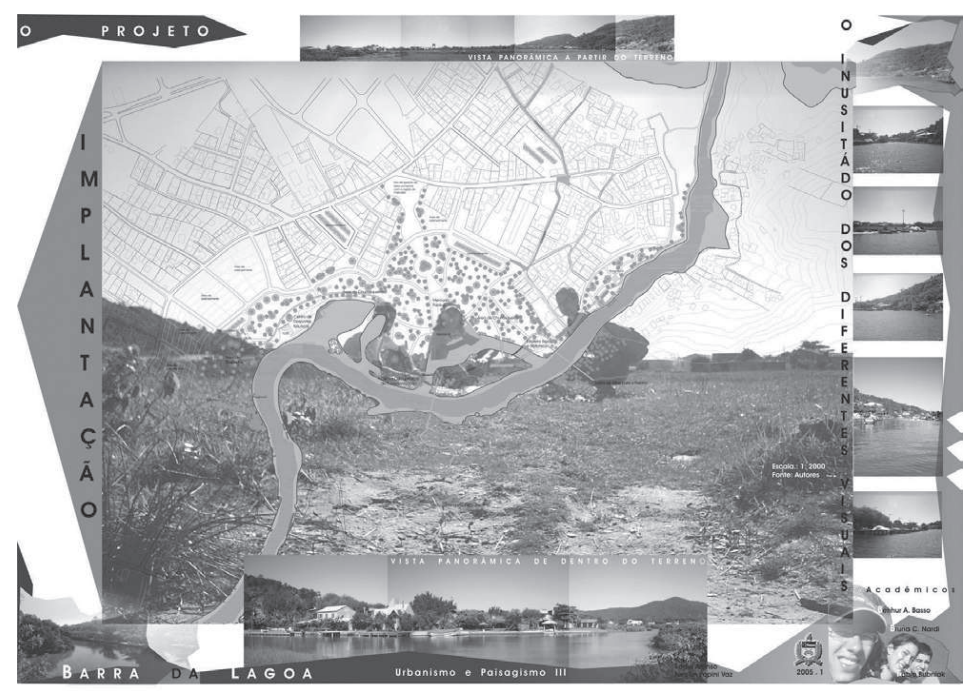

Figura 3: Implantação 1:1000

3. Detalhar na escala 1:200 um fragmento de uma das propostas (Figura 4):

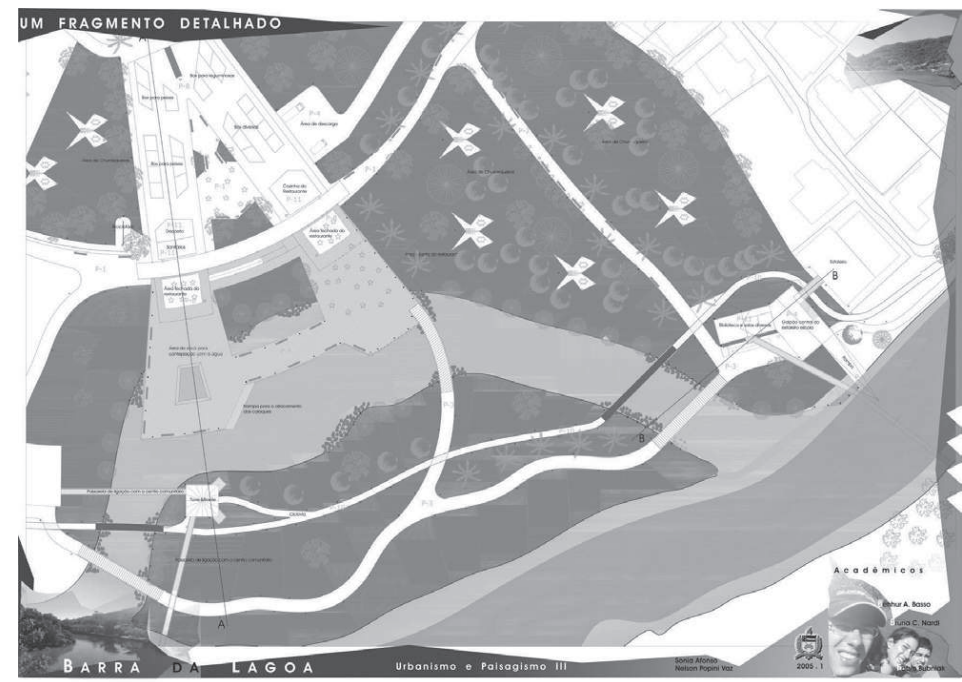

Figura 4: Implantação 1:200 
- Área menor do que 2 hectares, contendo $50 \%$ de espaços livres.

- Espaços livres com 50\% de área permeável (área verde).

- Terreno modelado de modo a criar ao menos três níveis diferentes.

- Mostrar como se dá o acesso, a circulação e o estacionamento de veículos.

- Criar ao menos um espaço livre contínuo ocupado por vegetação.

- Os percursos de pedestres devem respeitar o limite de 6\% de declividade.

- A água deve ser utilizada como elemento de projeto.

- A planta deverá representar o acesso ao térreo dos edifícios, os pisos e a vegetação adotados. As espécies vegetais especificadas em planta deverão comparecer na forma de um quadro que descreva as características das mesmas (Figura 5).

- As referências utilizadas na pesquisa deverão constar ao final da apresentação gráfica, juntamente com a bibliografia consultada.

4. Apresentação em pranchas Al (sem suporte rígido), contendo os seguintes elementos:

- Planta, axonométrica, cortes (Figura 6), croquis e texto esquemático explicativo do partido do projeto.

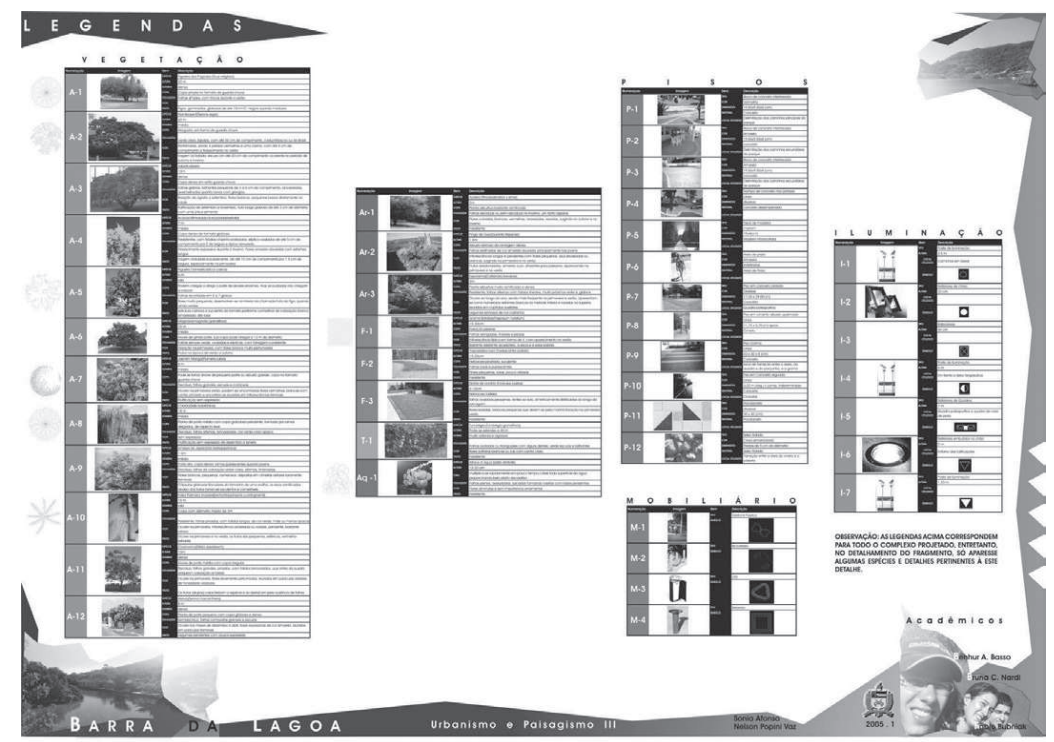

Figura 5: Vegetação, pisos, mobiliário, iluminação
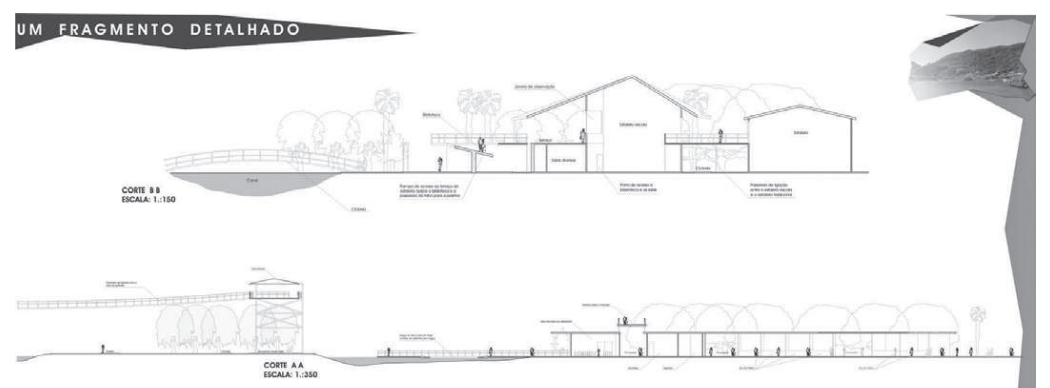

Figura 6: Cortes e croquis
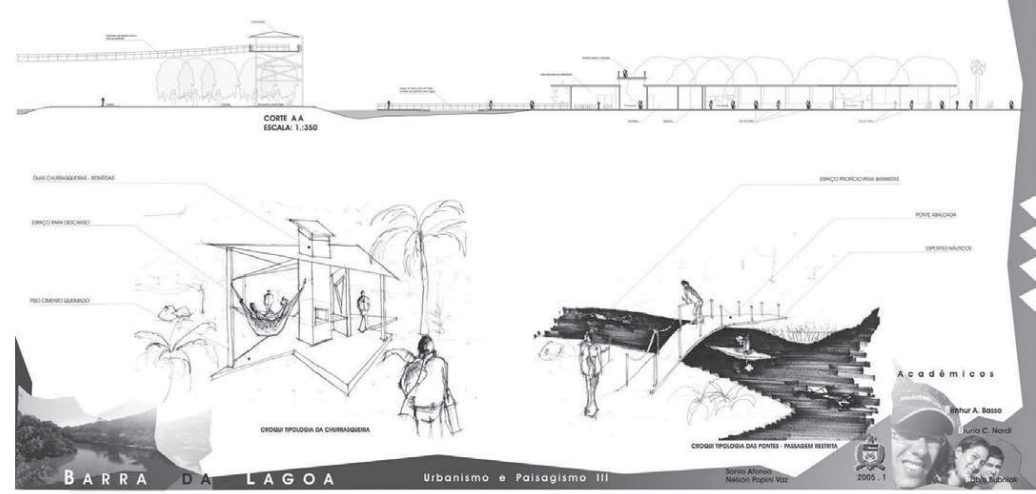


\section{Conclusões}

A experiência de trabalhar de modo interdisciplinar o Urbanismo e o Paisagismo tem revelado aspectos positivos nos produtos oferecidos pelos estudantes, conforme atesta o trabalho sobre a Barra da Lagoa.

A possibilidade de escolha da cidade e da área urbana de intervenção tem propiciado o aprofundamento do estudo em semestres posteriores do curso, em alguns casos chegando a culminar em trabalhos de finais de graduação.

Levantamos então algumas questões quanto a procedimentos e métodos.

1. O contexto do trabalho do ateliê de projetos é definido pela possibilidade de interação entre estudantes, entre estudantes e professores da disciplina, mas também de outros assessores de variada formação e prática. Considerando-se que o caráter essencial da experiência até agora levada a efeito seja a interdisciplinaridade, ela tem-se limitado à disponibilidade apenas de profissionais arquitetos. Busca-se compensar esse limite recomendando que os estudantes busquem contatos externos à disciplina e também à própria UFSC.

Essa condição poderá ser melhorada ao se revisar a experiência no âmbito da reforma curricular, cujo estudo se inicia agora no âmbito do Curso de Graduação.

Somente a reestruturação dos procedimentos de ateliê poderá contribuir para esse aperfeiçoamento.

2. Outra questão colocada refere-se ao uso da informática na elaboração e exposição dos trabalhos. Julga-se que o domínio do grafismo manual apresenta vantagens no aprofundamento da experiência de analisar e criar formas e modelos espaciais.

A insistência em estimular a prática do desenho por parte de todos os estudantes, pelo menos no início dos trabalhos, ou seja, em sua parte especulativa e criativa, tem encontrado resistência sobretudo face às facilidades oferecidas pelo CAD e similares e à sua débil formação no setor.

A co-presença em sala de aula parece ser enriquecedora, entretanto a deficiência de disponibilidade dos equipamentos de informática em número suficiente na escola tem forçado os estudantes a trabalhar fora de sala nos exercícios, reduzindo a possibilidade de contato entre eles mesmos e também com professores e outros prováveis assessores do corpo docente. Ao mesmo tempo afasta a possibilidade de se estabelecer normas para o uso desse equipamento, seguindo critérios pedagógicos.

Uma discussão mais criteriosa dos aspectos pedagógicos do uso dessas ferramentas poderá oferecer referências para se criar normas de uso.

3. A comunicação entre as pessoas é essencial em trabalhos interdisciplinares, sobretudo para a compreensão correta dos temas abordados: a clareza e a precisão de linguagem, o domínio do tempo disponível, o uso de material de apoio.

Verifica-se deficiência na experiência pregressa dos estudantes em relação à discussão e apresentação oral dos temas e dos projetos.

Julga-se que o desenvolvimento da capacidade de comunicação em âmbito técnico e científico poderia ser mais trabalhada em etapas anteriores do curso, permitindo maior produtividade e eficácia na abordagem das questões, tanto no trabalho em equipe quanto nos seminários e painéis programados para o conjunto da turma.

Um maior desenvolvimento dessa experiência poderá inclusive favorecer a integração desses trabalhos no âmbito da extensão, com indivíduos e comunidades externas ao setor e à própria Universidade. 


\section{Agradecimentos}

Agradecemos a colaboração de Bruna C. Nardi, Benhur A. Basso, Fábio Bubniak autores do Projeto para a Barra da Lagoa, bem como ao Arq. César Coelho e a Diego Fagundes, bolsisas do $\mathrm{CNPq}$, pelo tratamento das imagens e abstract.

\section{Notas}

(1) PósARQ - Programa de Pós-Graduação em Arquitetura e Urbanismo disponível em www.posarq.ufsc.br.

(2) AU-Cidade - Programa de Pós-Graduação em Urbanismo, História e Arquitetura da Cidade. Disponível em: http://www.pgau-cidade.ufsc.br/index2.html

(3) A professora Sonia Afonso teve oportunidade de cursar estágio docência na FAUUSP, nas disciplinas de Introdução ao Paisagismo, Parques e TGI, sob a supervisão dos professores Silvio Macedo e Vladimir Bartalini, quando teve oportunidade de trazer para a UFSC estas experiências de ensino que foram aqui adaptadas ao reunir a experiência de urbanismo do prof. Nelson Popini Vaz.

(4) AFONSO, Sonia; VAZ, Nelson Popini. Urbanismo e Paisagismo III. Site da professora Sonia Afonso. Disponível em: http://www.arq.ufsc.br/ soniaa/graduacao.htm

(5) AFONSO, Sonia. Urbanização de Encostas - A Ocupação do Morro da Cruz. Dissertação orientada pelo Prof. Dr. José Cláudio Gomes, defendida na FAUUSP em 1992.

(6) AFONSO, Sonia de. Encostas - A Ocupação do Morro da Cruz. Trabalho Programado 2. Estudo Geotécnico. Anexo ao mestrado. São Paulo. FAUUSP. 1992.

(7) AFONSO, Sonia. Urbanização de Encostas: Crises e Possibilidades. O Morro da Cruz como um Referencial de Arquitetura da Paisagem. Orientada pelo Prof. Dr. Silvio Soares Macedo, defendida na FAUUSP em 1999.

(8) VAZ, Nelson Popini. Centro Histórico de Florianópolis. Espaço do Ritual. Florianópolis, EdUFSC. 1992. Dissertação de Mestrado orientada pelo Prof. Dr. Hélio Romito de Almeida, defendida no GCN/UFSC em 1989.

9) VAZ, Nelson Popini. La Place Publique comme Espace de Communication. Orientada pelo Prof. Dr. Georges Knaebel, defendida no Instituto de Urbanismo de Paris, Universidade de Paris XII em 2003.

\section{Bibliografia}

ARANTES, Otília B. F. O lugar da arquitetura depois dos modernos. São Paulo: Nobel / Edusp, 1993, p. 95-155.

ASHIHARA, Yoshinobu. El diseño de espacios exteriores. Barcelona: Gustavo Gili, 1982.

BROOKS, John. Room outside. A new approach to garden design. Londres: Thames \& Hudson, 1969.

BUNJI, M. (Ed.). Pocket Parks. Process Architecture, Tokyo, Process Architecture Co., n. 78, 1991 (1888).

CARR, Stephen; FRANCIS, Mark; RIVLIN, Leam; STONE, A. M. Public space. Cambridge: Cam Univ Press, 1992.

CARUSO, Mariléa. O desmatamento da Ilha de Santa Catarina de 1500 aos dias atuais. Florianópolis: UFSC, 1983.

DAVIS, David A.; WALKER, Theodore. Plan graphics. Nova York: Van Nostrand-Reinhold, 1990.

DOURADO, Guilherme M. (Org.). Visões da paisagem. São Paulo: ABAP, 1997.

FERRARI, Celson. Curso de Planejamento Urbano Integrado. São Paulo: Pioneira, 1982.

GRAU, Eros R. Direito urbano. São Paulo: Revista dos Tribunais, 1993.

HOUGH, Michael. Naturaleza y ciudad: planificacion urbana y processos ecologicos. Barcelona: G. Gili, 1998.

KLIAS, Rosa G. Parques urbanos de São Paulo e sua evolução na cidade. São Paulo: Pini, 1993.

KOSTOFF, Spiro. The city shaped. Urban patterns and meanings through history. Boston: Bullfinch Press, 1991.

LACAZE, Jean-Paul. Os métodos do urbanismo. Campinas: Papirus, 1993.

LAMAS, José M. R. G. Morfologia urbana e desenho da cidade. Lisboa: Fundação C. Gulbenkian e JNICT, 1992.

LYLE, John T. Design for human ecosystems. Nova York: Van Nostrand Reinhold, 1985.

LEFEBVRE, Henri. Espacio y política. Barcelona: Península, 1976.

LOBATO, Roberto C. O espaço urbano. São Paulo: Ática, 1989.

MACEDO Silvio S. Espaços livres. Paisagem e Ambiente. São Paulo, FAUUSP, n. 7, p. 69-89, 1995.

. Quadro do paisagismo no Brasil. São Paulo: Projeto Quapá, 1999.

MARX, Murillo A. Cidade brasileira. São Paulo: Melhoramentos / Edusp, 1980.

MASCARÓ, Juan L. Desenho urbano e custos de urbanização. Porto Alegre: DC Luzzatto, 1989. 
MONTERO, Marta I. Burle Marx. Paisajes líricos. Buenos Aires: Iris, 1997.

REID, Grant W. From concept to form in landscape design. Nova York: Van Nostrand Reinhold, 1993.

RODRIGUES, R.; LEITÃO F. H. Matas ciliares. Conservação e recuperação. São Paulo: Edusp, 2000.

RUANO, Miguel. Eco-urbanismo. Barcelona: Gustavo Gili, 1999.

SANTOS, Milton. Metamorfoses do espaço habitado. São Paulo: Hucitec, 1988. p. 75-85.

A natureza do espaço. São Paulo: Hucitec, 1996. p. 50 - 71.

SENNETT, Richard. Carne e pedra. São Paulo: Record, 1997.

SPIRN, Anne W. O Jardim de Granito. A natureza no desenho da cidade. São Paulo: Edusp, 1995 (1984).

SPREIREGEN, Paul D. Compendio de arquitectura urbana. Barcelona: G. Gili, 1973 (1965).

STEENBERGEN, C.; REH, W. Arquitectura y paisaje. La proyectación de los grandes jardines europeus. Barcelona: G. Gili, 2001.

STEINITZ Carl. A framework for planning, practice and education. In: YOKOHARI, Makoto (Ed.) Process Architecture Tóquio, n. 127, 1994.

WEBB, Michael. The city square. Londres: Thames \& Hudson, 1990.

WILHEIM, Jorge. Urbanismo no subdesenvolvimento. Rio de Janeiro: Saga, 1969. 